Literature Reviews

\title{
A Review on Effects of Bisphenol a on Reproductive, Endocrine Systems and its Influencing Mechanism
}

\author{
${ }^{2}$ Ganghui Ye, ${ }^{3}$ Liting Zheng, ${ }^{2}$ Chang Meng, ${ }^{2,4}$ Yuefeng Dong, ${ }^{2}$ Hongyan Xu and ${ }^{1,2}$ Qinglu Wang \\ ${ }^{1}$ College of Sports and Health, Shandong Sport University, Jinan, 330013, China \\ ${ }^{2}$ Key Laboratory of Biomedical Engineering and Technology of Shandong High School, \\ Qilu Medical University, Zibo, 255213, China \\ ${ }^{3}$ The First Dongguan Affiliated Hospital of Guangdong Medical Univerisity, Dongguan, 523710, China \\ ${ }^{4}$ School of clinical medicine, Binzhou Medical University, Yantai, 264003, China
}

\author{
Article history \\ Received: 28-05-2021 \\ Revised: 15-10-2021 \\ Accepted: 21-10-2021 \\ Corresponding Author: \\ Qinglu Wang \\ College of Sports and Health, \\ Shandong Sport University, \\ China \\ Email: Wq1_zcq@126.com
}

\begin{abstract}
Background and purpose: Bisphenol A (BPA) is a pervasive environmental toxicant with known adverse effects on human immune system and nervous system et al. Although, BPA is widely known to affect endocrine function in animals, the linkage between human exposure to BPA and human reproductive function is still not clearly clarified. Results: Systematic review of all articles about BPA and human reproductive function identified in SCOPUS and PubMed. Literature was summarized in narrative form and results are presented per category. Some observational surveys investigating the relationship between BPA exposure and human reproductive and/or endocrine function are inconsistent. Conclusion: Our review integrates the studies of BPA on reproductive and/or endocrine system in recent years, mainly explains the effects of BPA on these systems and provides the basis for subsequent studies on BPA.
\end{abstract}

Keywords: Bisphenol A, Endocrine Disruptor, Reproductive Hormone, Semen Quality

\section{Introduction}

The monomer bisphenol $\mathrm{A}$ is a synthetic phenolic compound widely utilized for the manufacturing of polycarbonate and epoxy resins dedicated to food containers, such as cans and water dispensers. Global demand growth for BPA is expected to approximate 6$10 \% / y$ (Wright-Walters et al., 2011). Today, it is one of the highest-yield chemicals in the world, produced with more than 8 billion pounds yearly and sent roughly 100 tons into the atmosphere per year (Rubin 2011). Everyone is exposed to BPA through skin and inhalation; besides, these polymers can release BPA into water and food (Hernandez et al., 2019) and, it can be detectable in urine from the vast majority of Americans (Schug et al., 2011).

Endocrine Disrupting Chemicals (EDCs) are widely distributed in the environment, both natural or synthetic compounds can disrupt the endocrine system though imitating or antagonizing the endogenous hormones (Bhandari et al., 2015). BPA, as one of the most widespread and plentiful EDCs, can stimulate natural hormones to alter the reproductive endocrine system, which bring a negative effect on reproductive physiological functions (Caserta et al., 2011) and eventually influence entire populations (Yuan et al., 2015) Fig. 1.

Up to now, the effects of EDCs on reproductive physiology and endocrine system has not been systematically clarified. Thus, given such critical effect on reproductive and endocrine systems, we summarize briefly the regulatory role of BPA in reproductive related factors.

\section{Materials and Methods}

Our studies was conducted by systematic literature retrieval in Medline, Web of Science and PubMed databases. We identified the following search terms: "Bisphenol A" AND "reproduction" OR "endocrine" OR "androgen" OR “estrogen" OR "exposure” OR "hormone" OR “estradiol” OR "testosterone" OR "sperm" OR "sperm function" OR "spermatogenesis" OR semen quality OR "sexual function" and searched out the relevant literature. All data involved in related studies of animal as well as human and relevant reviews on the linkage between BPA and reproductive, endocrine systems were included in our study. Data were categorized and summarized according to the various aspects on which BPA may effect, 
such as effects on hormones and its influencing mechanisms. The list of the genes, enzymes and hormones involved throughout the whole paper is listed with their acronyms and full title in Table 1 . The genes mentioned is presented in lowercase italics.

\section{BPA Effects Endocrine and Reproductive}

There is evidence that BPA has similar chemical structure to estrogen and may be involved in the actions towards estrogen and androgen receptor system at fairly low doses by acting as agonists or antagonists for Estrogen Receptor $\alpha(\mathrm{ER} \alpha)$ and Estrogen Receptor $\beta(\mathrm{ER} \beta)$ (Kinch et al., 2015). Accumulating evidence including rodent and in vitro studies supports that BPA is able to bind to androgen receptor or estrogen receptor so that it has estrogenic as well as anti-androgenic impacts (Alonso-Magdalena et al., 2012; Melzer et al., 2011).

BPA interferes with hormone biosynthesis and metabolism through the role of endogenous ligands, leading to unbalance of endocrine system (Diamanti-Kandarakis et al., 2009), which proved that BPA may influence reproductive function via various hormone-mediated mechanisms. BPA may intervene with human cellular steroidogenesis by means of strong combination to human ER (Takeuchi et al., 2006) and influence the production of steroid hormones by intervening the expression of steroid synthetase (Zhou et al., 2008), change levels of steroid hormone and induce reproductive and embryo toxic effects (Mlynarčíková et al., 2005).

In addition, it has been demonstrated in animal studies that BPA has the unfavorable impacts on male reproductive health, which is evidenced by obstacle of spermatogenesis and steroidogenesis, poor sperm quality, male infertility and sex disorders (Peretz et al., 2014). There are also some studies showing that BPA reduces production of testosterone during male development, induces prostate diseases, affects spermatogenesis (Yeung et al., 2011) and results in apoptosis of male germ cells and Sertoli cells (Li et al., 2009; Qian et al., 2014). Therefore, aberrant hormone levels could be one crucial mechanism. Below we will respectively introduce the effects of BPA on related hormones, proteins or genes and their mechanisms of action Fig. 2.

\section{BPA Effects Testosterone}

\section{Effect of BPA on Testosterone in Human body}

Adequate studies have found a long-term decline in human testosterone levels (Andersson et al., 2007; Travison et al., 2007). From the perspective of working exposure, evidenced the negative relationship between serum Free Testosterone (FT) levels and urinary BPA levels on occupational BPA exposure (Zhou et al., 2013). From the angle of infertility, Den Hond et al. (2015) discovered the inverse relationship between testosterone levels in infertile male and urinary and blood plasma BPA concentrations (Den Hond et al., 2015). Likewise, the adverse association between free androgen index (an indicator for FT) and urinary BPA concentrations was detected in men diagnosed as infertile (Meeker et al., 2010).

Many experiments in humans have shown that BPA reduces the production of $\mathrm{AD}$ that a upstream molecular of T. There is a cross-sectional study on 592 men from China, which revealed the correlation between a high BPA exposure and a reduced AD level in blood (Liu et al., 2015). A study recruited 281 male workers exposed to epoxy resin from 4 factories and also discovered that BPA concentrations measured in serum were adversely correlated with AD level (Zhuang et al., 2015).

Instead, in a Lassen's study, it was indicated that BPA was positively linked with serum TT (total testosterone) and FT in urinary of young men (Lassen et al., 2014) and Galloway's findings also agree with another experiments of adult Italian, which suggested that BPA had a positive correlation with testosterone (Galloway et al., 2010).

At the same time, some experiments have shown that BPA exposure has no relationship with testosterone. In a human study, no adverse correlation with testosterone was discovered (Liang et al., 2017), although as assessed by serum Gonadotropins (Gn), including LH and FSH, BPA concentrations in urinary is linked to testicular dysfunction. Based on an epidemiology study, Mendiola and his colleagues found that BPA may affect the levels of Sex Hormone Binding Globulin (SHBG) and FAI instead of TT levels (Mendiola et al., 2010) and conjectured that the signal of increased LH and FSH may not suffice to induce the alteration of serum TT level. In a research of exposure to BPA diglycidyl ether and mixed organic solvents, it was indicated that urinary BPA was barely related with FT (Hanaoka et al., 2002).

\section{Effect of BPA on Testosterone in Animal (Non- Human)}

Besides, similar results were existed in animals experiments as well, there are studies indicating that pre- and postnatal BPA exposure can reduce testosterone levels in male offspring (Cardoso et al., 2011; Ma et al., 2017; Tanaka et al., 2006). Regarding pre-pubertal or pubertal exposures, the obvious drop in testosterone (Wisniewski et al., 2015) and epididymal sperm counts have been observed in rodent studies after BPA exposure (Herath et al., 2004). Rats are one of the best models for medical research. In adult male rats, Tohei et al. (2001) confirmed the decline of plasma testosterone levels in male adult rats after treatment by BPA in contrast with control group. Gurmeet et al. (2014) had proved that extremely low doses of BPA at which the adverse effects are not observed can negatively influence spermatogenesis, deprive seminiferous tubules of sperm and decrease levels to plasma testosterone significantly. At the same time, there is a study expressing that prenatal BPA exposure 
didn't alter testosterone levels of prepuberal male rats (Gámez et al. 2014).

\section{Mechanism of BPA Influencing Testosterone}

The main source of testosterone is Leydig cells, followed by adrenal cortex reticular bands. Leydig cells secrete testosterone Hypothalamus-PituitaryGonad Axis (HPGA). As for the later form, testosterone is synthesized from cholesterol and the specific process of testosterone synthesis is shown in Fig. 3. BPA can affect testosterone secretion in Leydig cells by acting on several key enzymes, such as steroidogenic acute Regulatory protein (StAR), cytochrome P450 11A1 (CYP11A1), aromatase cytochrome P450 (CYP19/P450arom), cytochrome P450 17A1 (CYP17A1) and 3ß-hydroxysteroid dehydrogenase (3$\beta$-HSD).in two forms: Basal secretion and gonadotropin-induced secretion regulated by the
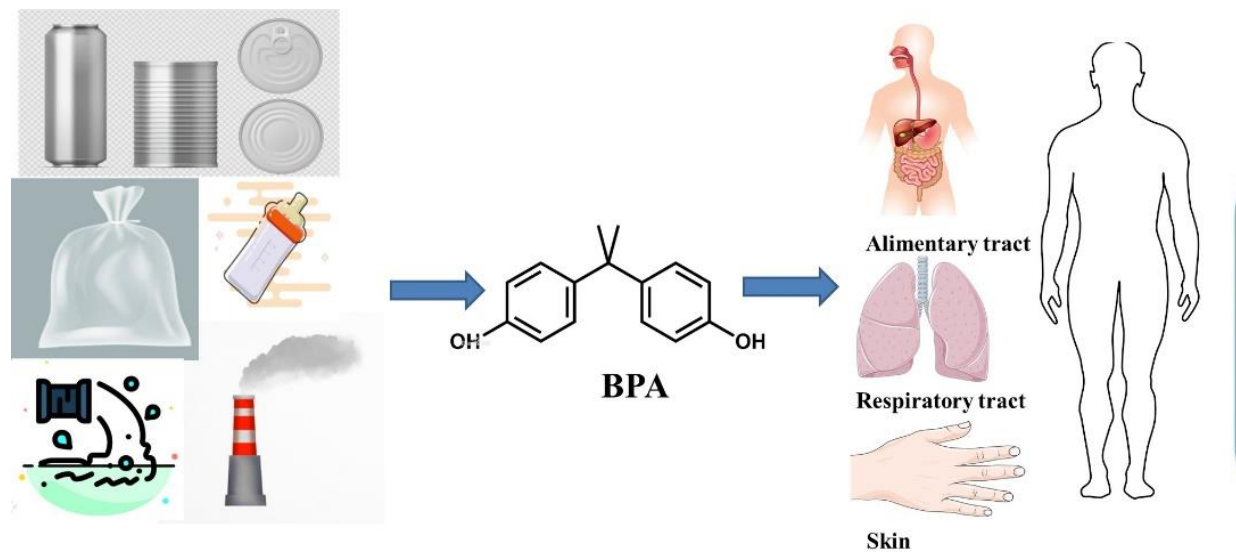

1. Altered endocrine and reproductive function.

2. Altered Neurodevelopment

3. Obesity

4. Heart disease

5. Increased risk of cancer

...

Skin

Fig. 1: The ways of BPA exposure through alimentary tract, respiratory tract and skin and its adverse effects on the human body

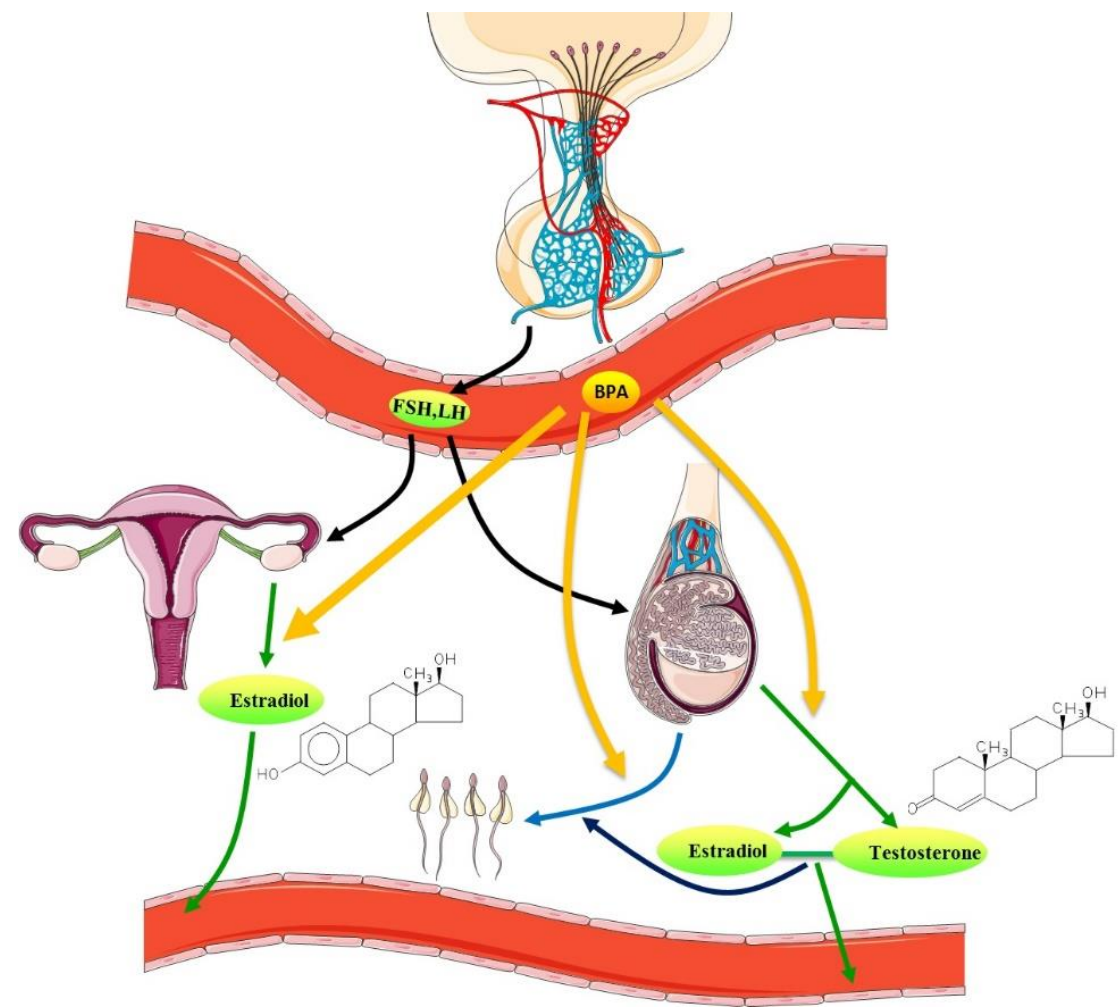

Fig. 2: Effect of BPA on reproductive endocrine system. BPA could make influences in the testis and ovary, then affect the hormone levels, have negative effects on reproductive endocrine system. Acronyms: Luteinizing Hormone (LH) and Follicle Stimulating Hormone (FSH) 

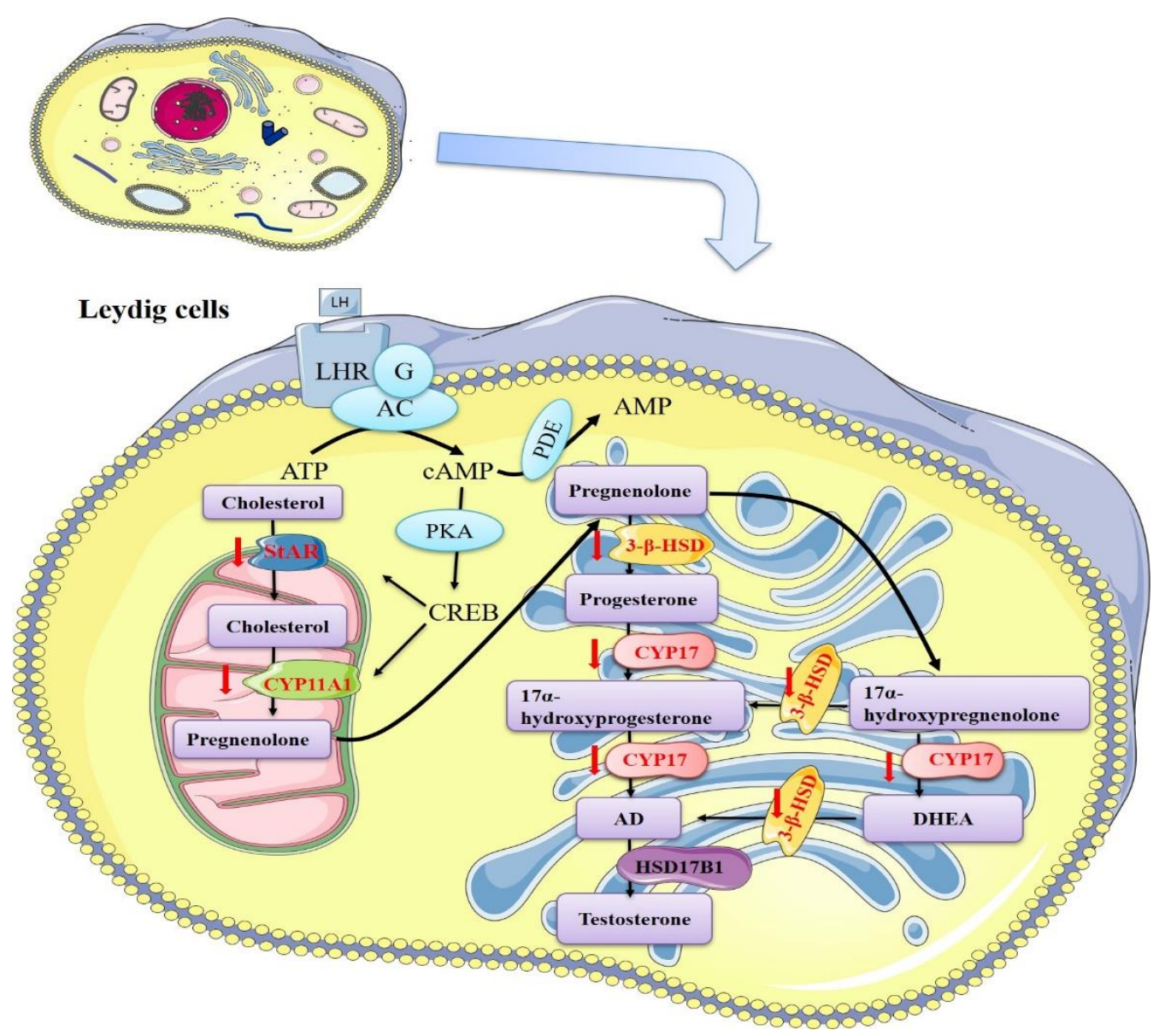

Fig. 3: The action sites of BPA exposure on pathway of testosterone production. BPA could influence the production of testosterone through changing the expression of related genes and steroidogenic enzymes. The BPA action sites were marked in red font a and the red arrows were used to define the impacts (The same as in the following figures). Acronyms: Luteinizing Hormone (LH), Luteinizing Hormone Receptor (LHR), GTP binding protein (G), Adenylate Cyclase (AC), Protein Kinase A (PKA), Phosphodiesterase (PDE), cAMP-Response Element Binding protein (CREB), Steroidogenic Acute Regulatory Protein (StAR), Cytochrome P450 11A1 (CYP11A1), 3 $\beta$-Hydroxysteroid dehydrogenase (3- $\beta$-HSD), Estradiol 17- $\beta$-dehydrogenase 1 (HSD17B1), Cytochrome P450 17 (CYP17), Androstenedione (AD), Dehydroepiandrosterone (DHEA)

Table 1: Abbreviations Table

\begin{tabular}{llll}
\hline Acronym & Full title & Acronym & Full title \\
\hline $3-\beta$-HSD & 3 $\beta$-Hydroxysteroid dehydrogenase & G & GTP binding protein \\
ABCA1 & ATP binding cassette subfamily A member 1 & HPGA & Hypothalamus-pituitary-gonad axis \\
AC & Adenylate cyclase & HSD17B1 & Estradiol 17- $\beta$-dehydrogenase 1 \\
AD & Androstenedione & INB & Inhibin B \\
AHR & Aryl hydrocarbon receptor & IVF & In-vitro fertilization \\
CREB & cAMP-response element binding protein & LH & Luteinizing hormone \\
CYP11A1 & Cytochrome P450 11A1 & LHR & Luteinizing hormone receptor \\
CYP17A1 & Cytochrome P450 17A1 & PDE & Phosphodiesterase \\
CYP19 & Aromatase cytochrome P450 & PKA & Protein Kinase A \\
DHEA & Dehydroepiandrosterone & ROS & Reactive oxygen species \\
E2 & Estradiol & SHBG & Sex hormone binding globulin \\
Er $\alpha$ & Estrogen receptor $\alpha$ & StAR & Steroidogenic acute regulatory protein \\
Er $\beta$ & Estrogen receptor $\beta$ & SOD & Superoxide dismutase \\
FSH & Follicle stimulating hormone & T & Testosterone \\
FSHR & Follicle stimulating hormone receptor & TT & Total testosterone \\
FT & Free testosterone & & \\
\hline
\end{tabular}


StAR

StAR, a transporter protein localized on the outer mitochondrial membrane, is a necessary regulator of steroid hormone biosynthesis, mainly to mediate transport of cholesterol into the mitochondrial inner membrane and present it to P450scc (CYP11A1), which is also a ratelimiting enzyme regulating synthesis of the related hormones (Ho et al., 2018; Selvaraj et al., 2015). Transportation of cholesterol in Leydig cells is mediated by StAR, which carriages it from the outer membrane of the mitochondria to the inner membrane.

The results of (Ma et al., 2017) and Yang et al. (2019) respectively found that, in male offspring of mice and pup, the mRNA expression level of star in BPA-treated was considerably declined in comparison with the result in the control group. Another study involving the model organism $C$. elegans, also demonstrated BPA exposure negatively impacted the expression of StAR (Chen et al., 2019). A reasonable explanation is that BPA can regulate phosphorylation of StAR, inhibiting its activation. Therefore, it can be concluded that BPA inhibits the transport of cholesterol by decreasing the expression of StAR, thereby inhibiting testosterone production.

\section{CYP11A1}

Several significant enzymes participate in steroidogenesis and convert cholesterol to testosterone in the form of catalysis. P450scc, the enzyme encoded by cyp 11a1, regulates the first step of steroidogenesis. The over-expression of cypllal partly exists in endocrine cells, including adrenal cortical cells, Leydig cells and ovarian follicular membrane cells (Hu et al., 2004).

It is widely known that P450 enzyme is one of the important targets of BPA (Sanderson 2006) and it has been shown that BPA has the ability to activate steroidogenic genes via the JNK/c-Jun signaling pathway, thus disrupting the testicular hormone environment (Lan et al., 2017). On maternal BPA exposure, it is demonstrated that CYP11A1 expression of male pup germ cell was obviously lower than the control group (Yang et al., 2019). Similarly, several studies validated that BPA exposure throughout the entire pregnancy in mice has effects on downregulating the expression of CYP11A in male offspring (Lv et al., 2019; Ma et al., 2017).

\section{CYP19}

Aromatase (P450 arom) encoded by cyp19 is another vital enzyme in steroidogenesis. P450 arom has abilities of aromatizing androgen into estrogen. Thus, it acts as the main enzyme involved in biosynthesis of estrogen and androgen (Li and Rahman, 2008).

In male zebrafish adults, mRNA levels of cyp19 were found reduced in comparison with the blank group (Wang et al., 2019). In rat Leydig cells, Akingbemi et al., (2004) similarly validated that cyp17 and cyp19 are also down expression by $0.01 \mathrm{nM}$ BPA.

\section{CYP17A1}

CYP17A1 has both $17 \alpha$-hydroxylase and 17,20talyzes this conversion reaction, which can catalyze the conversion of progesterone to $17 \alpha$ hydroxyprogesterone or the conversion of pregnenolone to $17 \alpha$-hydroxyprogesterone. The reaction involves $17 \alpha$-hydroxylation and C17-20 testosterone can be produced by a few steps of the reaction.

Earlier research showed that BPA causes the inhibition of CYP17 expression in testis, thereby decreasing testosterone production (Ye et al., 2011; Zhang et al., 2011). Gonçalves et al. (2018) have shown that in TM3 murine Leydig cells exposed to low BPA concentrations, the related gene cyp17al and cyp19a1 were downregulated when the testosterone biosynthesis was inhibited.

\section{3- $\beta-H S D$}

In the process of the production of androgens, Dehydroepiandrosterone (DHEA) is converted into AD by $3-\beta$-HSD. BPA exposure can inhibit the AD level by decreasing the expression of $3-\beta-H S D$ (Qiu et al., 2013), thereby further affecting the production of testosterone adversely. Another study also showed that CYP11A1 and 3- $\beta$-HSD were down-expressed in male mice treated by BPA (Liu et al., 2021). Pregnancy exposure of BPA could reduce the expression of 3- $\beta$ levels and germ cell apoptosis.

Generally, it has been observed that BPA may suppress testicular functions of rodents in different growth periods via changing the expression of steroidogenic related enzymes (Nanjappa et al., 2012), which then influences synthesis of steroid hormones and circulating steroid levels. A majority of studies support that BPA exposure may reduce production of testosterone by means of downregulating the related genes, star, cyp11a and cyp19. In addition, the testicular histology changes influenced by BPA may similarly be linked to the down-regulation of such important enzymes' expression (Goncalves et al., 2018). Effect of BPA on Estradiol (E2)

\section{Effect of BPA on Estradiol in Human Body}

In a survey about infertile women, Mok-Lin have 
revealed that the BPA levels of urinary were adversely associated with the level of serum E2 (Mok-Lin et al., 2010). And after BPA exposure, several studies also supported a significant decrease in peak serum estradiol levels prior to oocyte extraction in women undergoing in vitro fertilization (IVF) (Bloom et al., 2011; Ehrlich et al., 2

0

1

2 Unlike mentioned above, Miao et al. (2015) suggested that women exposed to BPA had higher levels of E2 in their urine by contrast with unexposed. The study of Minatoya recruited 514 participants and showed that the BPA level in cord blood was weakly positive associated with E2 (Minatoya et al., 2017). Meanwhile, in an experiment on the correlation between maternal urinary phenol concentration and umbilical cord steroid hormone levels, no obvious correlation was revealed between BPA and estradiol level (Liu et al., 2016), which was in accordance with two small-scale surveys $(\mathrm{n}=41$ and $\mathrm{n}=74)$ (6Takeuchi and Tsutsumi, 2002; Takeuchi et al., 2004), showing serum BPA concentrations had no association with estradiol among women.

\section{Effect of BPA on Estradiol in Animal (Non-Human)}

Lee et al. (2014) discovered a significant decrease of female rats serum concentration of E2 after BPA exposure and proved its disturbance on the maintenance of normal Zvarian functions. Moreover, in female zebrafish, the Concentrations of E2 considerably descended following the BPA exposure concentration (Fang et al., 2016; Qilleneuve et al., 2012). In addition, Peretz's study, concerning exposure of BPA in rat vitro antral follicle, had also proved this pollutant had the ability to inhibit the production of E2 (Peretz et al., 2011), which can bear d resemblance to the study from Qi et al. (2020) Samardzija et al. (2018) found that $100 \mu \mathrm{M}$ BPA exposure concentration on granulosa cells of immature pat resulted in an obvious reduction in progesterone diosynthesis. In the female offspring of mice exposed b BPA, Ma's study also showed an increase of serum E2 concentration in offspring of mice (Ma et al., 2017).

\section{Mechanism of BPA Influencing E2}

o Estrogen is synthesized by granulosa cells and intimal Cells (the placenta also secretes estrogen) in female and by Leydig cell in male and the specific mechanism in female is shown in Fig. 4. The decrease in estrogen secretion Pevel indicates that the hormonal synthesis function of granulosa cells and intimal cells is impaired.

It has been found that high concentrations of BPA in the urine samples from infertile women are closely correlated with the reduced number of primordial follicles (Silvestris et al., 2017). BPA can interfere with follicular qevelopment (Chen et al., 2017; Zhu et al., 2018) and can

(2020) discovered that $10 \mu \mathrm{M}$ BPA treatments on human ovarian granulosa cell line led to an obvious reduction in $413 \mathrm{~s}$ progesterone biosynthesis. significantly suppress the proliferation of mouse granulosa cells and the effect was in a dose dependent manner (Xu et al., 2002). Yu et al. (2018) too found that BPA interfered with the formation of primordial follicles through the estrogen receptor pathway in c h i $\mathrm{c}$

$\mathrm{k}$ Adult female rats of long-term BPA exposure can lead to a decrease in expression of StAR and P450 aromatase (Lee et al., 2013). Studies on production of steroid hormone in the ovarian granulosa cells from pigs showed that the key genes of steroidogenesis (star, cyp 11a1, 3- $\beta$ $\left.h_{s} d\right)$ were significantly down-regulated after BPA fxposure (Mlynarcikova and Scsukova 2018). Similar to the above study, Peretz et al. (2011b) proved that the mRNA levels of star, 3- $\beta$ - $h$ sd and cyp 11al were reduced In isolated follicles after BPA exposure. In a study about parental rare minnow, parental BPA exposure can inhibit offspring ovarian development via decreasing the number of mature oocytes and significantly affect the steroid genes cyp1la1, cyp17a1, cyp19al and star at the Branscriptional level (Zhu et al., 2021). And several studies about rat ovary also concluded that BPA trends to disturb the Steroidogenesis process via its suppression effect on StAR and $\mathrm{P} 450$ aromatase, thereby blocking E2 production (Lee et al., 2013; Peretz et al., 2011; Ziv-Gal et al., 2013). And it was proved that down-regulation of cyp19 Eranscription also exists in the placental cell line JEG-3 (Xu et al., 2019). Altered expression levels in these enzymes and genes are fundamentally crucial for steroidogenesis. On the contrary, in human granulosa aells, Qi et al. (2020) found that low dose BPA treatment dramatically reduced the expression of StAR and have a pegative effect on progesterone biosynthesis via the epregulation of ATP binding cassette subfamily A member 1 (ABCA1) which is a reverse cholesterol transport that mediates its export. And though experiments concerning granulosa cells from immature mice showed that BPA can elevate the expression of StAR, CYP11A1 and 3- $\beta$-HSD, Samardzija et al. (2018) observed that exposure to BPA can break up cholesterol homeostasis so that decrease the basal and the FSHstimulated progesterone production, which further affects èstrogen production.

Aromatic Hydrocarbon Receptor (AHR) is a ligand-dependent transcription factor (Ichihara et al., 2019). It had been shown that various environmental poisons can activate AHR which is largely distributed among the cytoplasm (Barouki et al., 2012). And it has Been demonstrated that AHR is essential, both physiologically and pathologically (Zhao et al., 2020). AHR was proved to regulate cyp19 expression when decrease level of ovarian estrogen (Baba et al., 2005). b e 
Ziv-Gal et al. (2013) designed the experiments to explore the influences of BPA on follicle function, observing BPA could act on AHR and influence the expression of $\mathrm{Bcl} 2$, an anti-apoptotic factor closely related to follicular atresia. They thought BPA can influence AHR signaling pathway and development of follicles to affect the endocrine system including reducing E2 levels. Further, Lee et al. (2013) observed a decline in E2 levels of ovarian follicular cells after BPA treatment, discovered an elevated count in apoptotic caspase- 3 positive cells at the same time, which were able to cause follicular atresia and luteal degeneration.

Contrasting with the above mechanism, there are still a large amount of surveys showing that exposure to BPA is positively correlated with E2 concentration. As mentioned above, the Déchaud et al. (1999) 's study is different from the result mentioned here. Furthermore, since it own the structure similar to E2, BPA has estrogenic activity and could competitively bind to SHBG to increase the E2 concentration in the serum. These arguments supported experiments in which BPA is positively correlated with E2, perhaps these are why some experiments back positive correlations. Similarly, the studies in which BPA has nothing to do with E2 can also be understood.

\section{Effect of BPA on Semen Quality and Male Sexual Function}

It is acknowledged that inhibin can be synthesized in Sertoli cells and its concentration functions as an indicator which can rate the Sertoli function of Sertoli cell. Compared with fertile men, it is observed that the expression of Inhibin B (INB) are greatly decreased in men with fertility disorders (Kumanov et al., 2006), which was in accordance with earlier studies that revealed BPA exposure was associated with abnormal sperm morphology and reduced sperm density (Li et al., 2011).

BPA could reduce testosterone production and affect the function of prostate and testis as well as spermatogenesis (Yeung et al., 2011). From the perspective of BPA work exposure, in several studies of men occupationally exposed to BPA, outcome was found that the exposure is related with declining sperm quality, concentration, motility and male sexual dysfunction, including reduced libido or erectile dysfunction, etc. (Adoamnei et al., 2018; Cariati et al., 2019; Li et al., 2010a; 2010b; 2011).

In addition, animal experiments have also found the negative influences of BPA on male reproductive health (Liu et al., 2021; Peretz et al., 2014). Several toxicological surveys have suggested prenatal or perinatal exposure to BPA in rodents results in varieties of disadvantageous reproductive consequences, including epididymal weight loss, reduced daily sperm production (Salian et al., 2009a, b) and increased prostate weight (Nagel et al., 1997). Experiments about prepubertal rat testis also showed the outcome that exposure to BPA is confirmed to reduce sperm counts and quality and alter the testicular histology (Balci et al., 2020). Therefore, abnormal hormone levels may be one significant mechanism.

However, there are still some studies that do not match the above. One cohort studies (Goldstone et al., 2015) assessed the correlation between BPA and semen quality among reproductive aged men and found little evidence showing that BPA reduced the semen quality of the population tested. One cross-sectional study (Mendiola et al., 2010) showed no significant correlation between any semen parameters and BPA concentrations in urine. A study of maternal exposure to BPA showed that testicular function does not adversely affect testicular function in adulthood even if there is a potentially weak positive correlation with certain testicular function parameters detected (Hart et al., 2018).

It is widely known that Sertoli cells are crucial to maintain male reproductive functions. Previous experiments have demonstrated that BPA can induce apoptosis in Sertoli cells and male germ cells, thereby inhibiting sperm production (Li et al., 2009; Qian et al., 2014). Studies examined on rat Sertoli cells have shown that BPA can inhibit their vitality and induce apoptosis (Qiu et al., 2013; Wang et al., 2015). Wang et al. (2015) observed that BPA exposure could induce apoptosis of Sertoli cells mediated by the Pten/Akt signaling pathway Fig. 5. In turn, Qi et al. (2014) confirmed that BPA also induces Sertoli cell apoptosis via activating the JNKs/ P38 pathway. In early puberty, BPA disrupts sperm production and changes the spermatogenic tubule epithelial morphology, it can increase Reactive Oxygen Species (ROS) production while decreasing the antioxidant activity of catalase and Superoxide Dismutase (SOD) enzymes (Abubakar et al., 2020; Ullah et al., 2019). There are also studies supporting BPA to induce apoptosis in Sertoli cells by causing excessive ROS production and mitochondrial dysfunction (Wang et al., 2017). which was also in accordance with the study of Barbonetti et al. (2016) that pro-oxidative/apoptotic mitochondrial dysfunction can influence sperm integrity, as well. The toxicity of BPA on male reproductive showed that DNA/histone methylation change make contribution to the decreased of sperm quality (Zhu et al., 2020). 


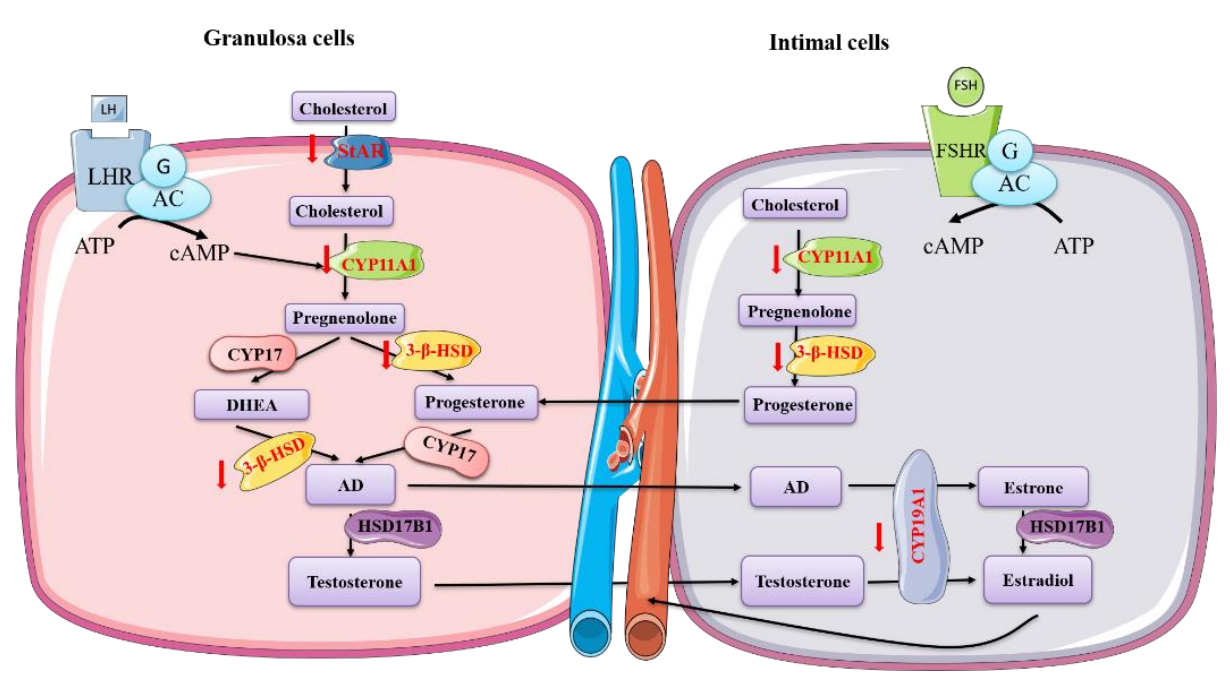

Fig. 4: Effect of BPA exposure on pathway of estrogen synthesis. BPA could influence the synthesis of estrogen through changing the expression of related genes and steroidogenic enzymes. The signaling pathway molecules highlighted in red are BPA sites of action. Acronyms: Luteinizing Hormone (LH), Luteinizing Hormone Receptor (LHR), Follicle Stimulating Hormone (FSH), Follicle Stimulating Hormone Receptor (FSHR), GTP binding protein (G), Adenylate cyclase (AC), Protein Kinase A (PKA), Phosphodiesterase (PDE), cAMP-response element binding protein (CREB), Steroidogenic Acute Regulatory Protein (StAR), Cytochrome P450 11A1 (CYP11A1), 33-Hydroxysteroid Dehydrogenase (3- $\beta$-HSD), Estradiol 17- $\beta$-Dehydrogenase 1 (HSD17B1), Cytochrome P450 17 (CYP17), Aromatase cytochrome P450 (CYP19/P450arom), Androstenedione (AD), Dehydroepiandrosterone (DHEA).

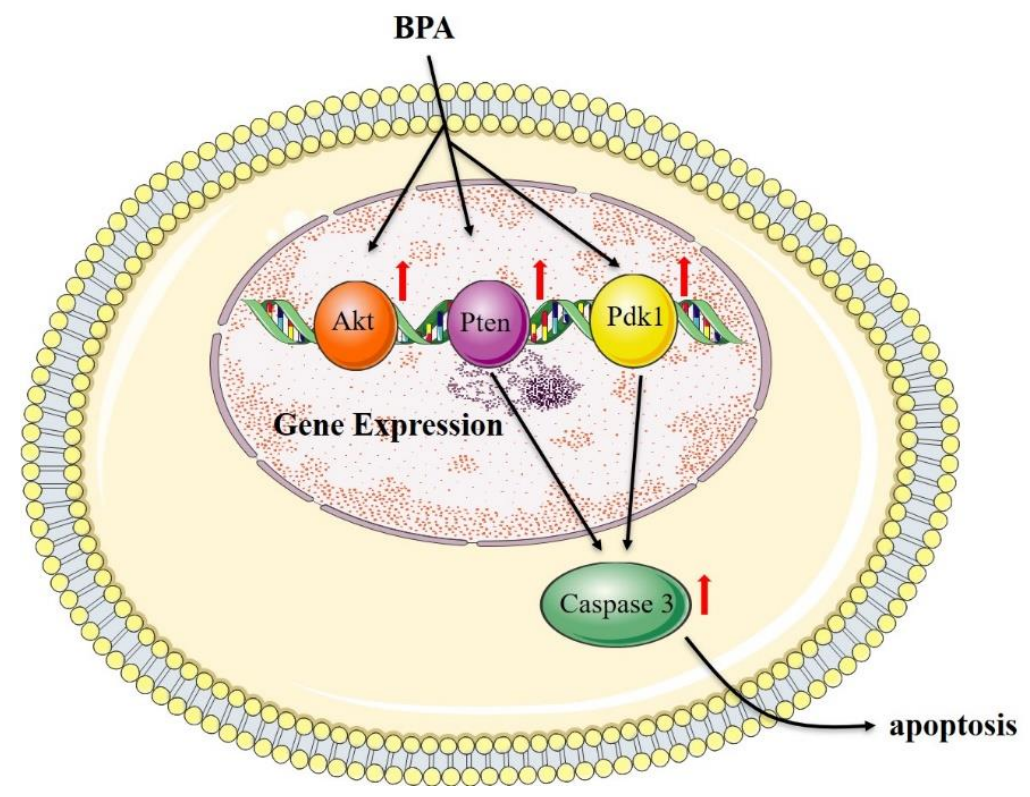

Fig. 5: As described in's findings. BPA could induce the apoptosis of rat Sertoli cells through Pten/Akt signaling pathway (Wang et al., 2015)

\section{Conclusion}

There is no doubt that BPA as an environmental interferer has an adverse effect on human endocrine and reproduction. This review gathers some researches articles, concludes the impacts of BPA on reproductive hormone, sperm quality, male sexual function and discusses their generation and change mechanisms. There are differences in the results of studies, the reasons for which are various. First, people are differences in 
lifestyle, eating habits, education levels, age, gender, etc. of subjects in different studies and experimental animal also have disparity in dose, method of administration and time of exposure to interferers. Second, people may be exposed to a variety of EDCs in their living environment, often in a state of "co-exposed" and some studies suggest that "co-exposure" may amplify the health effects of BPA (Vandenberg et al., 2007), therefore, the study of the impact of BPA on human health needs to consider the impact of other EDCs that may exist. Third, some studies have a small sample size and some studies do not consider the effects of confounding factors. In addition, several surveys assessed the impacts of BPA exposure on the reproductive system by testing serum, urine BPA levels even semen parameters of different sorts of samples, which may explain inconsistent results (Vitku et al., 2016). All of these factors may be the reasons why the experimental results are inconsistent. In general, BPA inhibits spermatogenesis by the direct effect of disturbing the Sertoli cells function and the indirect influence of reducing testosterone production.

Further summary of the endocrine and reproduction have made in this review according to the recent literature. Meanwhile, Due to the ubiquity of BPA in the environment, we can only provide some theories of BPA toxicity, but still cannot solve the effects of BPA on the body. Next, on the basis of BPA toxicity as a causative factor of the endocrine and reproductive system abnormalities, proposed a new prospective that if we can research a new biomarker to detect the occurrence of abnormalities.

\section{Acknowledgment}

This work was supported by grants from the Natural Scientific Foundation of Shandong Province, China (ZR2018MH038), the National Natural Scientific Foundation of China (31701042) and the Zibo City Integration Development Project (2019ZBXC320).

\section{Author's Contributions}

Ganghui Ye: Contributed to conceptualization, design and writing.

Liting Zheng: Contributed to writing and revising.

Chang Meng and Yuefeng Dong: Contributed to drafting.

Hongyan Xu: Contributed to editing.

Qinglu Wang: Contributed to conceptualization and design.

\section{Ethics}

Neither the entire paper nor any part of its content has been published or has been accepted elsewhere. It is not being submitted to any other journal. The authors declare that there are no conflicts of interest in this study.

\section{References}

Abubakar, A. A., Ali, A. K., Ibrahim, S. M., Handool, K. O., Khan, M. S., Noordin, M. M., ... \& Loqman, M. Y. (2020). Generation of Open Metatarsal Fracture in Rats: A Model for Secondary Fracture Healing. SciMedicine Journal, 2(4), 197-211. doi.org/10.28991/SciMedJ-2020-0204-2

Adoamnei, E., Mendiola, J., Vela-Soria, F., Fernández, M. F., Olea, N., Jørgensen, N., ... \& Torres-Cantero, A. M. (2018). Urinary bisphenol A concentrations are associated with reproductive parameters in young men. Environmental research, 161, 122-128. doi.org/10.1016/j.envres.2017.11.002

Akingbemi, B. T., Sottas, C. M., Koulova, A. I., Klinefelter, G. R., \& Hardy, M. P. (2004). Inhibition of testicular steroidogenesis by the xenoestrogen bisphenol $\mathrm{A}$ is associated with reduced pituitary luteinizing hormone secretion and decreased steroidogenic enzyme gene expression in rat Leydig cells. Endocrinology, 145(2), 592-603.

doi.org/10.1210/en.2003-1174

Alonso-Magdalena, P., Ropero, A. B., Soriano, S., García-Arévalo, M., Ripoll, C., Fuentes, E., ... \& Nadal, Á. (2012). Bisphenol-A acts as a potent estrogen via non-classical estrogen triggered pathways. Molecular and cellular endocrinology, 355(2), 201-207. doi.org/10.1016/j.mce.2011.12.012

Andersson, A. M., Jensen, T. K., Juul, A., Petersen, J. H., Jørgensen, T., \& Skakkebæk, N. E. (2007). Secular decline in male testosterone and sex hormone binding globulin serum levels in Danish population surveys. The Journal of Clinical Endocrinology \& Metabolism, 92(12), 4696-4705. doi.org/10.1210/jc.2006-2633

Baba, T., Mimura, J., Nakamura, N., Harada, N., Yamamoto, M., Morohashi, K. I., \& Fujii-Kuriyama, Y. (2005). Intrinsic function of the aryl hydrocarbon (dioxin) receptor as a key factor in female reproduction. Molecular and cellular biology, 25(22), 10040-10051. doi.org/10.1128/MCB.25.22.1004010051.2005

Balci, A., Ozkemahli, G., Erkekoglu, P., Zeybek, N. D., Yersal, N., \& Kocer-Gumusel, B. (2020). Histopathologic, apoptotic and autophagic, effects of prenatal bisphenol A and/or di (2-ethylhexyl) phthalate exposure on prepubertal rat testis. Environmental Science and Pollution Research, 27(16), 20104-20116. https://link.springer.com/article/10.1007/s11356020-08274-6

Barbonetti, A., Castellini, C., Di Giammarco, N., Santilli, G., Francavilla, S., \& Francavilla, F. (2016). In vitro exposure of human spermatozoa to bisphenol A induces pro-oxidative/apoptotic mitochondrial dysfunction. Reproductive Toxicology, 66, 61-67. doi.org/10.1016/j.reprotox.2016.09.014 
Barouki, R., Aggerbeck, M., Aggerbeck, L., \& Coumoul, X. (2012). The aryl hydrocarbon receptor system. doi.org/10.1515/dmdi-2011-0035

Bhandari, R. K., Deem, S. L., Holliday, D. K., Jandegian, C. M., Kassotis, C. D., Nagel, S. C., ... \& Rosenfeld, C. S. (2015). Effects of the environmental estrogenic contaminants bisphenol A and 17 $\alpha$-ethinyl estradiol on sexual development and adult behaviors in aquatic wildlife species. General and comparative endocrinology, 214, 195-219. doi.org/10.1016/j.ygcen.2014.09.014.

Bloom, M. S., Kim, D., Vom Saal, F. S., Taylor, J. A. Cheng, G., Lamb, J. D., \& Fujimoto, V. Y. (2011). Bisphenol A exposure reduces the estradiol response to gonadotropin stimulation during in vitro fertilization. Fertility and sterility, 96(3), 672-677. doi.org/10.1016/j.fertnstert.2011.06.063

Campen, K. A., Kucharczyk, K. M., Bogin, B., Ehrlich, J. M., \& Combelles, C. M. (2018). Spindle abnormalities and chromosome misalignment in bovine oocytes after exposure to low doses of bisphenol A or bisphenol S. Human Reproduction, 33(5), 895-904. doi.org/10.1093/humrep/dey050

Cardoso, N., Pandolfi, M., Lavalle, J., Carbone, S., Ponzo, O., Scacchi, P., \& Reynoso, R. (2011). Probable gamma-aminobutyric acid involvement in bisphenol A effect at the hypothalamic level in adult male rats. Journal of physiology and biochemistry, 67(4), 559-567.

https://link.springer.com/article/10.1007/s13105011-0102-6

Cariati, F., D’Uonno, N., Borrillo, F., Iervolino, S., Galdiero, G., \& Tomaiuolo, R. (2019). Bisphenol a: an emerging threat to male fertility. Reproductive Biology and Endocrinology, 17(1), 1-8. https://link.springer.com/article/10.1186/s12958018-0447-6

Caserta, D., Mantovani, A., Marci, R., Fazi, A., Ciardo, F., La Rocca, C.,... \& Moscarini, M. (2011). Environment and women's reproductive health. Human reproduction update, 17(3), 418-433. doi.org/10.1093/humupd/dmq061

Chen, W., Lau, S. W., Fan, Y., Wu, R. S., \& Ge, W. (2017). Juvenile exposure to bisphenol A promotes ovarian differentiation but suppresses its growthPotential involvement of pituitary follicle-stimulating hormone. Aquatic toxicology, 193, 111-121. doi.org/10.1016/j.aquatox.2017.10.008

Chen, Y., Panter, B., Hussain, A., Gibbs, K., Ferreira, D., \& Allard, P. (2019). BPA interferes with StARmediated mitochondrial cholesterol transport to induce germline dysfunctions. Reproductive Toxicology, 90, 24-32.

doi.org/10.1016/j.reprotox.2019.08.001
Déchaud, H., Ravard, C., Claustrat, F., de la Perrière, A. B., \& Pugeat, M. (1999). Xenoestrogen interaction with human sex Hormone-Binding Globulin (hSHBG) 1. Steroids, 64(5), 328-334. doi.org/10.1016/S0039-128X(98)00114-7

Den Hond, E., Tournaye, H., De Sutter, P., Ombelet, W., Baeyens, W., Covaci, A.,... \& D'Hooghe, T. (2015). Human exposure to endocrine disrupting chemicals and fertility: A case-control study in male subfertility patients. Environment international, 84, 154-160. doi.org/10.1016/j.envint.2015.07.017

Diamanti-Kandarakis, E., Bourguignon, J. P., Giudice, L. C., Hauser, R., Prins, G. S., Soto, A. M., ... \& Gore, A. C. (2009). Endocrine-disrupting chemicals: An Endocrine Society scientific statement. Endocrine reviews, 30(4), 293-342. doi.org/10.1210/er.2009-0002

Ehrlich, S., Williams, P. L., Missmer, S. A., Flaws, J. A., Ye, X., Calafat, A. M., ... \& Hauser, R. (2012). Urinary bisphenol A concentrations and early reproductive health outcomes among women undergoing IVF. Human reproduction, 27(12), 3583-3592. doi.org/10.1093/humrep/des328

Fang, Q., Shi, Q., Guo, Y., Hua, J., Wang, X., \& Zhou, B. (2016). Enhanced bioconcentration of bisphenol A in the presence of nano-TiO2 can lead to adverse reproductive outcomes in zebrafish. Environmental science \& technology, 50(2), 1005-1013. doi.org/10.1021/acs.est.5b05024

Galloway, T., Cipelli, R., Guralnik, J., Ferrucci, L., Bandinelli, S., Corsi, A. M., ... \& Melzer, D. (2010). Daily bisphenol A excretion and associations with sex hormone concentrations: Results from the InCHIANTI adult population study. Environmental health perspectives, 118(11), 1603-1608. doi.org/10.1289/ehp.1002367

Gámez, J. M., Penalba, R., Cardoso, N., Ponzo, O., Carbone, S., Pandolfi, M., ... \& Reynoso, R. (2014). Low dose of bisphenol A impairs the reproductive axis of prepuberal male rats. Journal of physiology and biochemistry, 70(1), 239-246. https://link.springer.com/article/10.1007/s13105013-0298-8

Goldstone, A. E., Chen, Z., Perry, M. J., Kannan, K., \& Louis, G. M. B. (2015). Urinary bisphenol A and semen quality, the LIFE Study. Reproductive Toxicology, 51, 7-13. doi.org/10.1016/j.reprotox.2014.11.003

Goncalves, G. D., Semprebon, S. C., Biazi, B. I., Mantovani, M. S., \& Fernandes, G. S. A. (2018). Bisphenol A reduces testosterone production in TM3 Leydig cells independently of its effects on cell death and mitochondrial membrane potential. Reproductive Toxicology, 76, 26-34. doi.org/10.1016/j.reprotox.2017.12.002 
Gurmeet, K. S. S., Rosnah, I., Normadiah, M. K., Das, S., \& Mustafa, A. M. (2014). Detrimental effects of bisphenol A on development and functions of the male reproductive system in experimental rats. EXCLI journal, 13, 151.

https://www.ncbi.nlm.nih.gov/pmc/articles/PMC4 464354/

Hanaoka, T., Kawamura, N., Hara, K., \& Tsugane, S. (2002). Urinary bisphenol A and plasma hormone concentrations in male workers exposed to bisphenol A diglycidyl ether and mixed organic solvents. Occupational and environmental medicine, 59(9), 625-628. doi.org/10.1136/oem.59.9.625

Hart, R. J., Doherty, D. A., Keelan, J. A., Minaee, N. S., Thorstensen, E. B., Dickinson, J. E., ... \& Handelsman, D. J. (2018). The impact of antenatal Bisphenol A exposure on male reproductive function at 20-22 years of age. Reproductive biomedicine online, 36(3), 340-347. doi.org/10.1016/j.rbmo.2017.11.009

Herath, C. B., Jin, W., Watanabe, G., Arai, K., Suzuki, A. K., \& Taya, K. (2004). Adverse effects of environmental toxicants, octylphenol and bisphenol $\mathrm{A}$, on male reproductive functions in pubertal rats. Endocrine, 25(2), 163-172. https://link.springer.com/article/10.1385/ENDO:2 5:2:163

Hernandez, A. F., Buha, A., Constantin, C., Wallace, D. R., Sarigiannis, D., Neagu, M., ... \& Tsatsakis, A. (2019). Critical assessment and integration of separate lines of evidence for risk assessment of chemical mixtures. Archives of toxicology, 93(10), 2741-2757. https://link.springer.com/article/10.1007/s00204019-02547-x

Ho, H. J., Shirakawa, H., Giriwono, P. E., Ito, A., \& Komai, M. (2018). A novel function of geranylgeraniol in regulating testosterone production. Bioscience, biotechnology and biochemistry, 82(6), 956-962. doi.org/10.1080/09168451.2017.1415129

Hu, M. C., Hsu, H. J., Guo, C., \& Chung, B. C. (2004). Function of Cyp11a1 in animal models. Molecular and cellular endocrinology, 215(1-2), 95-100. doi.org/10.1016/j.mce.2003.11.024

Ichihara, S., Li, P., Mise, N., Suzuki, Y., Izuoka, K., Nakajima, T., ... \& Ichihara, G. (2019). Ablation of aryl hydrocarbon receptor promotes angiotensin II-induced cardiac fibrosis through enhanced c-Jun/HIF-1 $\alpha$ signaling. Archives of toxicology, 93(6), 1543-1553. https://link.springer.com/article/10.1007/s00204019-02446-1

Kinch, C. D., Ibhazehiebo, K., Jeong, J. H., Habibi, H. R., \& Kurrasch, D. M. (2015). Low-dose exposure to bisphenol A and replacement bisphenol $\mathrm{S}$ induces precocious hypothalamic neurogenesis in embryonic zebrafish. Proceedings of the National Academy of Sciences, 112(5), 1475-1480. https://www.pnas.org/content/112/5/1475.short
Kumanov, P., Nandipati, K., Tomova, A., \& Agarwal, A. (2006). Inhibin $\mathrm{B}$ is a better marker of spermatogenesis than other hormones in the evaluation of male factor infertility. Fertility and sterility, 86(2), 332-338

doi.org/10.1016/j.fertnstert.2006.01.022

Lan, H. C., Wu, K. Y., Lin, I. W., Yang, Z. J., Chang, A. A., \& Hu, M. C. (2017). Bisphenol A disrupts steroidogenesis and induces a sex hormone imbalance through c-Jun phosphorylation in Leydig cells. Chemosphere, 185, 237-246. doi.org/10.1016/j.chemosphere.2017.07.004

Lassen, T. H., Frederiksen, H., Jensen, T. K., Petersen, J. H., Joensen, U. N., Main, K. M., ... \& Andersson, A. M. (2014). Urinary bisphenol A levels in young men: Association with reproductive hormones and semen quality. Environmental health perspectives, 122(5), 478-484. doi.org/10.1289/ehp.1307309

Lee, H. S., Park, E. J., Oh, J. H., Moon, G., Hwang, M. S., Kim, S. Y., ... \& Hong, J. H. (2014). Bisphenol A exerts estrogenic effects by modulating CDK1/2 and p38 MAP kinase activity. Bioscience, biotechnology and biochemistry, 78(8), 1371-1375. doi.org/10.1080/09168451.2014.921557

Lee, S. G., Kim, J. Y., Chung, J. Y., Kim, Y. J., Park, J. E., Oh, S., ... \& Kim, J. M. (2013). Bisphenol A exposure during adulthood causes augmentation of follicular atresia and luteal regression by decreasing $17 \beta$-estradiol synthesis via downregulation of aromatase in rat ovary. Environmental health perspectives, 121(6), 663-669. doi.org/10.1289/ehp.1205823

Li, D. K., Zhou, Z., Miao, M., He, Y., Qing, D., Wu, T., ... \& Yuan, W. (2010a). Relationship between urine bisphenol-A level and declining male sexual function. Journal of andrology, 31(5), 500-506. doi.org/10.2164/jandrol.110.010413

Li, D., Zhou, Z., Qing, D., He, Y., Wu, T., Miao, M., ... \& Yuan, W. (2010b). Occupational exposure to bisphenol-A (BPA) and the risk of self-reported male sexual dysfunction. Human reproduction, 25(2), 519-527. doi.org/10.1093/humrep/dep381

Li, D. K., Zhou, Z., Miao, M., He, Y., Wang, J., Ferber, J., ... \& Yuan, W. (2011). Urine bisphenol-A (BPA) level in relation to semen quality. Fertility and sterility, 95(2), 625-630. doi.org/10.1016/j.fertnstert.2010.09.026

Li, X., \& Rahman, N. (2008). Impact of androgen/estrogen ratio: lessons learned from the aromatase over-expression mice. General and comparative endocrinology, 159(1), 1-9. doi.org/10.1016/j.ygcen.2008.07.025

Li, Y. J., Song, T. B., Cai, Y. Y., Zhou, J. S., Song, X., Zhao, X., \& Wu, X. L. (2009). Bisphenol A exposure induces apoptosis and upregulation of Fas/FasL and caspase-3 expression in the testes of mice. Toxicological sciences, 108(2), 427-436. doi.org/10.1093/toxsci/kfp024 
Liang, H., Xu, W., Chen, J., Shi, H., Zhu, J., Liu, X., ... \& Yuan, W. (2017). The association between exposure to environmental bisphenol $\mathrm{A}$ and gonadotropic hormone levels among men. PloS one, 12(1), e0169217. doi.org/10.1371/journal.pone.0169217

Liu, C., Xu, X., Zhang, Y., Li, W., \& Huo, X. (2016). Associations between maternal phenolic exposure and cord sex hormones in male newborns. Human Reproduction, 31(3), 648-656. doi.org/10.1093/humrep/dev327

Liu, X., Miao, M., Zhou, Z., Gao, E., Chen, J., Wang, J., ... \& Li, D. K. (2015). Exposure to bisphenol-A and reproductive hormones among male adults. Environmental toxicology and pharmacology, 39(2), 934-941. doi.org/10.1016/j.etap.2015.03.007

Liu, X., Wang, Z., \& Liu, F. (2021). Chronic exposure of BPA impairs male germ cell proliferation and induces lower sperm quality in male mice. Chemosphere, 262, 127880. doi.org/10.1016/j.chemosphere.2020.127880

Lv, Y., Li, L., Fang, Y., Chen, P., Wu, S., Chen, X., ... \& Ge, R. S. (2019). In utero exposure to bisphenol A disrupts fetal testis development in rats. Environmental Pollution, 246, 217-224. doi.org/10.1016/j.envpol.2018.12.006

Ma, S., Shi, W., Wang, X., Song, P., \& Zhong, X. (2017). Bisphenol A exposure during pregnancy alters the mortality and levels of reproductive hormones and genes in offspring mice. BioMed research international, 2017. doi.org/10.1155/2017/3585809

Meeker, J. D., Calafat, A. M., \& Hauser, R. (2010). Urinary bisphenol a concentrations in relation to serum thyroid and reproductive hormone levels in men from an infertility clinic. Environmental science \& technology, 44(4), 1458-1463.

doi.org/10.1021/es9028292

Melzer, D., Harries, L., Cipelli, R., Henley, W., Money, C., McCormack, P., ... \& Galloway, T. (2011). Bisphenol A exposure is associated with in vivo estrogenic gene expression in adults. Environmental health perspectives, 119(12), 1788-1793. doi.org/10.1289/ehp.1103809

Mendiola, J., Jørgensen, N. andersson, A. M., Calafat, A. M., Ye, X., Redmon, J. B., ... \& Swan, S. H. (2010). Are environmental levels of bisphenol A associated with reproductive function in fertile men? Environmental health perspectives, 118(9), 1286-1291. doi.org/10.1289/ehp.1002037

Miao, M., Yuan, W., Yang, F., Liang, H., Zhou, Z., Li, R., ... \& Li, D. K. (2015). Associations between bisphenol A exposure and reproductive hormones among female workers. International journal of environmental research and public health, 12(10), 13240-13250. doi.org/10.3390/ijerph121013240
Minatoya, M., Sasaki, S., Araki, A., Miyashita, C., Itoh, S., Yamamoto, J., ... \& Kishi, R. (2017). Cord blood bisphenol A levels and reproductive and thyroid hormone levels of neonates: The Hokkaido Study on Environment and Children's Health. Epidemiology, 28, S3-S9.

https://journals.lww.com/epidem/Abstract/2017/100 01/Cord_Blood_Bisphenol_A_Levels_and_Reprodu ctive_and.3.aspx

Mlynarcikova, A. B., \& Scsukova, S. (2018). Simultaneous effects of endocrine disruptor bisphenol A and flavonoid fisetin on progesterone production by granulosa cells. Environmental toxicology and pharmacology, 59, 66-73. doi.org/10.1016/j.etap.2018.03.001

Mlynarčíková, A., Kolena, J., Ficková, M., \& Scsuková, S. (2005). Alterations in steroid hormone production by porcine ovarian granulosa cells caused by bisphenol A and bisphenol A dimethacrylate. Molecular and cellular endocrinology, 244(1-2), 5762. doi.org/10.1016/j.mce.2005.02.009

Mok-Lin, E., Ehrlich, S., Williams, P. L., Petrozza, J., Wright, D. L., Calafat, A. M., ... \& Hauser, R. (2010). Urinary bisphenol A concentrations and ovarian response among women undergoing IVF. International journal of andrology, 33(2), 385-393. doi.org/10.1111/j.1365-2605.2009.01014. x

Nagel, S. C., vom Saal, F. S., Thayer, K. A., Dhar, M. G., Boechler, M., \& Welshons, W. V. (1997). Relative binding affinity-serum modified access (RBA-SMA) assay predicts the relative in vivo bioactivity of the xenoestrogens bisphenol A and octylphenol. Environmental health perspectives, 105(1), 70-76. doi.org/10.1289/ehp.9710570

Nanjappa, M. K., Simon, L., \& Akingbemi, B. T. (2012). The industrial chemical bisphenol A (BPA) interferes with proliferative activity and development of steroidogenic capacity in rat Leydig cells. Biology of reproduction, 86(5), 135-1. doi.org/10.1095/biolreprod.111.095349

Peretz, J., Gupta, R. K., Singh, J., Hernández-Ochoa, I., \& Flaws, J. A. (2011). Bisphenol A impairs follicle growth, inhibits steroidogenesis and downregulates rate-limiting enzymes in the estradiol biosynthesis pathway. Toxicological Sciences, 119(1), 209-217. doi.org/10.1093/toxsci/kfq319

Peretz, J., Vrooman, L., Ricke, W. A., Hunt, P. A., Ehrlich, S., Hauser, R., ... \& Flaws, J. A. (2014). Bisphenol A and reproductive health: update of experimental and human evidence, 2007-2013. Environmental health perspectives, 122(8), 775-786. https://doi.org/10.1289/ehp.1307728

Qi, J., Liu, L., Yang, J., Gao, X., \& Zhang, W. (2020). Bisphenol A decreases progesterone synthesis in human ovarian granulosa cells. Birth Defects Research, 112(20), 1843-1849. doi.org/10.1002/bdr2.1817 
Qi, S., Fu, W., Wang, C., Liu, C., Quan, C., Kourouma, A., ... \& Yang, K. (2014). BPA-induced apoptosis of rat Sertoli cells through Fas/FasL and JNKs/p38 MAPK pathways. Reproductive Toxicology, 50, 108-116. doi.org/10.1016/j.reprotox.2014.10.013

Qian, W., Zhu, J., Mao, C., Liu, J., Wang, Y., Wang, Q., ... \& Wang, J. (2014). Involvement of CaMCaMKII-ERK in bisphenol A-induced Sertoli cell apoptosis. Toxicology, 324, 27-34. doi.org/10.1016/j.tox.2014.06.001

Qiu, L. L., Wang, X., Zhang, X. H., Zhang, Z., Gu, J., Liu, L., ... \& Wang, S. L. (2013). Decreased androgen receptor expression may contribute to spermatogenesis failure in rats exposed to low concentration of bisphenol A. Toxicology letters, 219(2), 116-124. doi.org/10.1016/j.toxlet.2013.03.011

Rubin, B. S. (2011). Bisphenol A: an endocrine disruptor with widespread exposure and multiple effects. The Journal of steroid biochemistry and molecular biology, 127(1-2), 27-34.

doi.org/10.1016/j.jsbmb.2011.05.002

Salian, S., Doshi, T., \& Vanage, G. (2009). Neonatal exposure of male rats to Bisphenol A impairs fertility and expression of sertoli cell junctional proteins in the testis. Toxicology, 265(1-2), 56-67. doi.org/10.1016/j.tox.2009.09.012

Salian, S., Doshi, T., \& Vanage, G. (2009). Perinatal exposure of rats to Bisphenol A affects the fertility of male offspring. Life sciences, 85(21-22), 742-752. doi.org/10.1016/j.lfs.2009.10.004

Samardzija, D., Pogrmic-Majkic, K., Fa, S., Stanic, B., Jasnic, J., \& Andric, N. (2018). Bisphenol A decreases progesterone synthesis by disrupting cholesterol homeostasis in rat granulosa cells. Molecular and cellular endocrinology, 461, 55-63. doi.org/10.1016/j.mce.2017.08.013

Sanderson, J. T. (2006). The steroid hormone biosynthesis pathway as a target for endocrine-disrupting chemicals. Toxicological sciences, 94(1), 3-21. doi.org/10.1093/toxsci/kfl051

Schug, T. T., Janesick, A., Blumberg, B., \& Heindel, J. J. (2011). Endocrine disrupting chemicals and disease susceptibility. The Journal of steroid biochemistry and molecular biology, 127(3-5), 204-215. doi.org/10.1016/j.jsbmb.2011.08.007

Selvaraj, V., Stocco, D. M., \& Tu, L. N. (2015). Minireview: Translocator protein (TSPO) and steroidogenesis: A reappraisal. Molecular endocrinology, 29(4), 490-501. doi.org/10.1210/me.2015-1033

Silvestris, E., Cohen, M., Cornet, D., JacquessonFournols, L., Clement, P., Chouteau, J., ... \& Ménézo, Y. (2017). Supporting the one-carbon cycle restores ovarian reserve in subfertile women: Absence of correlation with urinary bisphenol A concentration. BioResearch open access, 6(1), 104-109. doi.org/10.1089/biores.2017.0016
Takeuchi, T., \& Tsutsumi, O. (2002). Serum bisphenol A concentrations showed gender differences, possibly linked to androgen levels. Biochemical and biophysical research communications, 291(1), 76-78. doi.org/10.1006/bbrc.2002.6407

Takeuchi, T., Tsutsumi, O., Ikezuki, Y., Kamei, Y., Osuga, Y., Fujiwara, T., ... \& Taketani, Y. (2006). Elevated serum bisphenol A levels under hyperandrogenic conditions may be caused by decreased UDP-glucuronosyltransferase activity. Endocrine journal, 0607070009-0607070009. doi.org/10.1507/endocrj .K06-025

Takeuchi, T., Tsutsumi, O., Ikezuki, Y., Takai, Y., \& Taketani, Y. (2004). Positive relationship between androgen and the endocrine disruptor, bisphenol A, in normal women and women with ovarian dysfunction. Endocrine journal, 51(2), 165-169. doi.org/10.1507/endocrj.51.165

Tanaka, M., Nakaya, S., Katayama, M., Leffers, H., Nozawa, S., Nakazawa, R., ... \& Kobayashi, S. (2006). Effect of prenatal exposure to bisphenol A on the serum testosterone concentration of rats at birth. Human \& experimental toxicology, 25(7), 369-373. doi.org/10.1191/0960327106ht638oa

Tohei, A., Suda, S., Taya, K., Hashimoto, T., \& Kogo, H. (2001). Bisphenol A inhibits testicular functions and increases luteinizing hormone secretion in adult male rats. Experimental biology and medicine, 226(3), 216-221. doi.org/10.1177/153537020122600309

Travison, T. G., Araujo, A. B., O’Donnell, A. B., Kupelian, V., \& McKinlay, J. B. (2007). A population-level decline in serum testosterone levels in American men. The Journal of Clinical Endocrinology \& Metabolism, 92(1), 196-202. doi.org/10.1210/jc.2006-1375

Ullah, A., Pirzada, M., Jahan, S., Ullah, H., \& Khan, M. J. (2019). Bisphenol A analogues bisphenol B, bisphenol $\mathrm{F}$ and bisphenol $\mathrm{S}$ induce oxidative stress, disrupt daily sperm production and damage DNA in rat spermatozoa: A comparative in vitro and in vivo study. Toxicology and industrial health, 35(4), 294-303. doi.org/10.1177/0748233719831528

Vandenberg, L. N., Hauser, R., Marcus, M., Olea, N., \& Welshons, W. V. (2007). Human exposure to bisphenol A (BPA). Reproductive toxicology, 24(2), 139-177. doi.org/10.1016/j.reprotox.2007.07.010

Villeneuve, D. L., Garcia-Reyero, N., Escalon, B. L., Jensen, K. M., Cavallin, J. E., Makynen, E. A., ... \& Ankley, G. T. (2012). Ecotoxicogenomics to support ecological risk assessment: A case study with bisphenol A in fish. Environmental science \& technology, 46(1), 51-59. doi.org/10.1021/es201150a 
Vitku, J., Heracek, J., Sosvorova, L., Hampl, R., Chlupacova, T., Hill, M., ... \& Starka, L. (2016). Associations of bisphenol A and polychlorinated biphenyls with spermatogenesis and steroidogenesis in two biological fluids from men attending an infertility clinic. Environment international, 89, 166-173. doi.org/10.1016/j.envint.2016.01.021

Wang, C., Fu, W., Quan, C., Yan, M., Liu, C., Qi, S., \& Yang, K. (2015). The role of Pten/Akt signaling pathway involved in BPA-induced apoptosis of rat sertoli cells. Environmental toxicology, 30(7), 793802. doi.org/10.1002/tox.21958

Wang, C., Qi, S., Liu, C., Yang, A., Fu, W., Quan, C., ... \& Yang, K. (2017). Mitochondrial dysfunction and $\mathrm{Ca} 2+$ overload in injured sertoli cells exposed to bisphenol A. Environmental toxicology, 32(3), 823831. doi.org/10.1002/tox.22282

Wang, Y. Q., Li, Y. W., Chen, Q. L., \& Liu, Z. H. (2019). Long-term exposure of xenoestrogens with environmental relevant concentrations disrupted spermatogenesis of zebrafish through altering sex hormone balance, stimulating germ cell proliferation, meiosis and enhancing apoptosis. Environmental Pollution, 244, 486-494. doi.org/10.1016/j.envpol.2018.10.079

Wisniewski, P., Romano, R. M., Kizys, M. M., Oliveira, K. C., Kasamatsu, T., Giannocco, G., ... \& Romano, M. A. (2015). Adult exposure to bisphenol A (BPA) in Wistar rats reduces sperm quality with disruption of the hypothalamic-pituitary-testicular axis. Toxicology, 329, 1-9. doi.org/10.1016/j.tox.2015.01.002

Wright-Walters, M., Volz, C., Talbott, E., \& Davis, D. (2011). An updated weight of evidence approach to the aquatic hazard assessment of bisphenol $\mathrm{A}$ and the derivation a new predicted no effect concentration (Pnec) using a non-parametric methodology. Science of the Total Environment, 409(4), 676-685. doi.org/10.1016/j.scitotenv.2010.07.092

Xu, H., Zhang, X., Ye, Y., \& Li, X. (2019). Bisphenol A affects estradiol metabolism by targeting CYP1A1 and CYP19A1 in human placental JEG-3 cells. Toxicology in Vitro, 61, 104615. doi.org/10.1016/j.tiv.2019.104615

Xu, J., Osuga, Y., Yano, T., Morita, Y., Tang, X., Fujiwara, T., ... \& Tsutsumi, O. (2002). Bisphenol A induces apoptosis and G2-to-M arrest of ovarian granulosa cells. Biochemical and Biophysical Research Communications, 292(2), 456-462. doi.org/10.1006/bbrc.2002.6644

Yang, Q., Sui, X., Cao, J., Liu, C., Zheng, S., Bao, M., ... \& Wu, K. (2019). Effects of exposure to Bisphenol A during pregnancy on the pup testis function. International journal of endocrinology, 2019. doi.org/10.1155/2019/6785289

Ye, L., Zhao, B., Hu, G., Chu, Y., \& Ge, R. S. (2011). Inhibition of human and rat testicular steroidogenic enzyme activities by bisphenol A. Toxicology letters, 207(2), 137-142. doi.org/10.1016/j.toxlet.2011.09.001
Yeung, B. H., Wan, H. T., Law, A. Y., \& Wong, C. K. (2011). Endocrine disrupting chemicals: Multiple effects on testicular signaling and spermatogenesis. Spermatogenesis, 1(3), 231-239. doi.org/10.4161/spmg.1.3.18019

Yu, M., Xu, Y., Li, M., Li, D., Lu, Y., Yu, D., \& Du, W. (2018). Bisphenol A accelerates meiotic progression in embryonic chickens via the estrogen receptor $\beta$ signaling pathway. General and comparative endocrinology, 259, 66-75. doi.org/10.1016/j.ygcen.2017.11.004

Yuan, M., Bai, M. Z., Huang, X. F., Zhang, Y., Liu, J., Hu, M. H., ... \& Jin, F. (2015). Preimplantation exposure to bisphenol A and triclosan may lead to implantation failure in humans. BioMed Research International, 2015. doi.org/10.1155/2015/184845

Zhang, X., Chang, H., Wiseman, S., He, Y., Higley, E., Jones, P., ... \& Hecker, M. (2011). Bisphenol A disrupts steroidogenesis in human H295R cells. Toxicological Sciences, 121(2), 320-327. doi.org/10.1093/toxsci/kfr061

Zhao, Y., Lin, J., Talukder, M., Zhu, S. Y., Li, M. Z., Wang, H. R., \& Li, J. L. (2020). Aryl hydrocarbon receptor as a target for lycopene preventing DEHPinduced spermatogenic disorders. Journal of agricultural and food chemistry, 68(15), 4355-4366. doi.org/10.1021/acs.jafc.9b07795

Zhou, Q., Miao, M., Ran, M., Ding, L., Bai, L., Wu, T., .. \& Li, D. K. (2013). Serum bisphenol-A concentration and sex hormone levels in men. Fertility and sterility, 100(2), 478-482. doi.org/10.1016/j.fertnstert.2013.04.017

Zhou, W., Liu, J., Liao, L., Han, S., \& Liu, J. (2008). Effect of bisphenol A on steroid hormone production in rat ovarian theca-interstitial and granulosa cells. Molecular and cellular endocrinology, 283(1-2), 12-18. doi.org/10.1016/j.mce.2007.10.010

Zhu, L., Liu, Y., Xue, X., Yuan, C., \& Wang, Z. (2021). BPA's transgenerational disturbance to transcription of ovarian steroidogenic genes in rare minnow Gobiocypris rarus via DNA and histone methylation. Science of The Total Environment, 762, 143055. doi.org/10.1016/j.scitotenv.2020.143055

Zhu, L., Yuan, C., Wang, M., Liu, Y., Wang, Z., \& Seif, M. M. (2020). Bisphenol A-associated alterations in DNA and histone methylation affects semen quality in rare minnow Gobiocypris rarus. Aquatic Toxicology, 226, 105580. doi.org/10.1016/j.aquatox.2020.105580

Zhu, X., Tian, G. G., Yu, B., Yang, Y., \& Wu, J. (2018). Effects of bisphenol A on ovarian follicular development and female germline stem cells. Archives of toxicology, 92(4), 1581-1591. https://link.springer.com/article/10.1007/s00204018-2167-2 
Zhuang, W., Wu, K., Wang, Y., Zhu, H., Deng, Z., Peng, L., \& Zhu, G. (2015). Association of serum bisphenol-A concentration and male reproductive function among exposed workers. Archives of environmental contamination and toxicology, 68(1), 38-45. https://link.springer.com/article/10.1007/s00244014-0078-7
Ziv-Gal, A., Craig, Z. R., Wang, W., \& Flaws, J. A. (2013). Bisphenol A inhibits cultured mouse ovarian follicle growth partially via the aryl hydrocarbon receptor signaling pathway. Reproductive toxicology, 42, 58-67.

doi.org/10.1016/j.reprotox.2013.07.022 